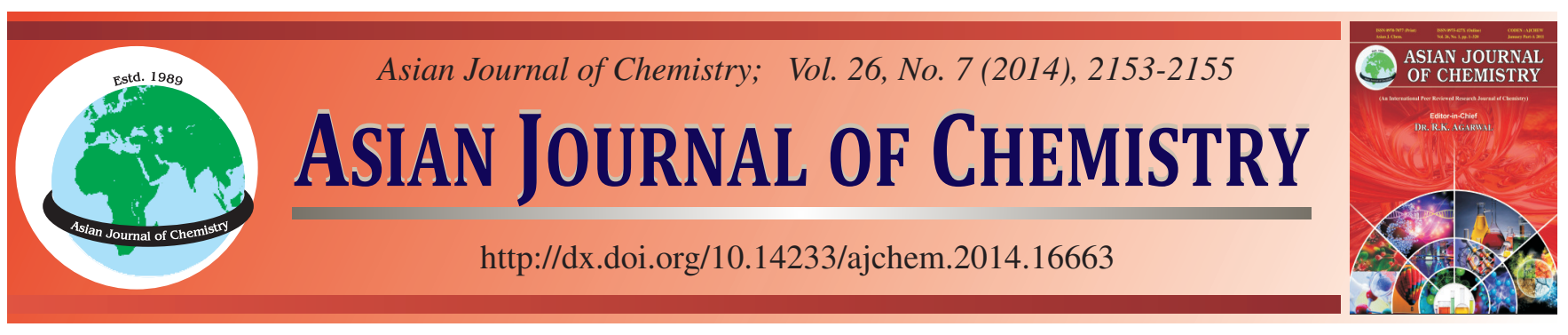

\title{
Preparation of NiO/Ni Nanocomposites Under Microwave Irradiation and Its Catalysis for Reduction of 4-Nitrophenol
}

\author{
JiUlONg Li and WeON BAE Ko*
}

Department of Chemistry, Sahmyook University, Seoul 139-742, Republic of Korea

*Corresponding author: Fax: +82 2 9795318; E-mail: kowbsahmyook@syu.ac.kr

Nickel(II) hydroxide nanocomposites were synthesized by a reaction of nickel(II) acetate tetrahydrate $\left[\mathrm{Ni}\left(\mathrm{CH}_{3} \mathrm{COO}\right)_{2} \cdot 4 \mathrm{H}_{2} \mathrm{O}\right]$ and sodium hydroxide in ethanol under microwave irradiation for $5 \mathrm{~min}$. The $\mathrm{NiO} / \mathrm{Ni}$ nanocomposites were then prepared by calcining the $\mathrm{Ni}(\mathrm{OH})_{2}$ nanocomposites in an electric furnace at $700{ }^{\circ} \mathrm{C}$ for $2 \mathrm{~h}$. The resulting heated products were examined by X-ray diffraction, scanning electron microscopy and transmission electron microscopy. In addition, the reduction of 4-nitrophenol with sodium borohydride and the $\mathrm{NiO} / \mathrm{Ni}$ nanocomposites as a catalyst was examined by UV-visible spectrophotometer.

Keywords: NiO/Ni nanocomposites, Microwave irradiation, Reduction of 4-nitrophenol, UV-visible spectrophotometer.

\section{INTRODUCTION}

Development of nanotechnology presents many new chemical subjects and provides new opportunities ${ }^{1}$. The synthesis of nanocomposites has been studied extensively over the last three decades. Nano-sized composites exhibit novel mechanical, magnetic, electronic and optical properties compared to their bulk counterparts ${ }^{2-6}$. Metal-metal oxide nanoparticles, such as $\mathrm{Cu} / \mathrm{Cu}_{2} \mathrm{O}^{7}, \mathrm{Zn} / \mathrm{ZnO}^{8}$ and $\mathrm{Sn} / \mathrm{SnO}_{2}{ }^{9,10}$, have potential in magnetic materials, gas sensors and catalysis ${ }^{11}$. Because of the easy reduction of cationic copper, zinc and tin species, the first preparation of the metallic nanocomposites is normally to reduce the corresponding metal cations with reducing agents under mild conditions, followed by the controlled oxidation of the outer layer with air or oxygen to form the metal/metal oxide nanocomposites ${ }^{7,8,11}$. The NiO/Ni nanocomposites are of great technical importance because nickel is used as a major component in numerous alloys for high temperature applications ${ }^{12-14}$. $\mathrm{NiO}$, a semiconductor metal oxide with a band gap of 3.6-4.0 eV, has potential applications, such as battery cathode ${ }^{15,16}$, catalyst ${ }^{17}$, gas sensors ${ }^{18}$, magnetic materials ${ }^{19,20}$ and electrochromic films ${ }^{21}$. A range of methods have been developed for the synthesis of $\mathrm{NiO}$ nanocomposites, such as sol-gel, hydrothermal, precipitation, emulsion, electrodeposition and sputtering ${ }^{22-25}$. In this study, the $\mathrm{Ni}(\mathrm{OH})_{2}$ nanocomposites were prepared by nickel(II) acetate tetrahydrate and sodium hydroxide in a liquid phase environment and the resulting $\mathrm{Ni}(\mathrm{OH})_{2}$ was calcined to prepare the $\mathrm{NiO} / \mathrm{Ni}$ nano- composites. The $\mathrm{NiO} / \mathrm{Ni}$ nanocomposites were characterized by X-ray diffraction (XRD), scanning electron microscopy (SEM) and transmission electron microscopy (TEM). The reduction of 4-nitrophenol with $\mathrm{NiO} / \mathrm{Ni}$ nanocomposites as a catalyst in the presence of sodium borohydride was examined by UV-visible spectrophotometer.

\section{EXPERIMENTAL}

$\mathrm{Ni}\left(\mathrm{CH}_{3} \mathrm{COO}\right)_{2} \cdot 4 \mathrm{H}_{2} \mathrm{O}, \mathrm{NaOH}$ and $\mathrm{C}_{2} \mathrm{H}_{5} \mathrm{OH}$ were obtained from Samchun Chemicals. 4-Nitrophenol was supplied by Sigma-Aldrich Co., Inc. $\mathrm{NaBH}_{4}$ was purchased by Kanto Chemical Co., Inc. The structures of nanomaterials were examined by XRD (Bruker, D8 Advance). The surfaces of NiO/ Ni nanocomposites were observed by SEM (JEOL Ltd, JSM6510 ) at an accelerating voltage of 0.5 to $30 \mathrm{kV}$. The morphology and crystallite size of samples were examined by TEM (JEOL Ltd, JEM-2010) at an acceleration voltage of $200 \mathrm{kV}$. UV-visible spectroscopy of samples was performed using a UV-visible spectrometer (Shimazu UV-1691PC).

Synthesis of the $\mathrm{NiO} / \mathrm{Ni}$ nanocomposites and catalytic reduction of 4-nitrophenol: The $\mathrm{NiO} / \mathrm{Ni}$ nanocomposites were prepared by a reaction of $50 \mathrm{mM}$ nickel(II) acetate tetrahydrate $\left[\mathrm{Ni}\left(\mathrm{CH}_{3} \mathrm{COO}\right)_{2} \cdot 4 \mathrm{H}_{2} \mathrm{O}\right]$ and $10 \mathrm{mM}$ sodium hydroxide. The chemicals were dissolved in the $25 \mathrm{~mL}$ ethanol as a liquid phase environment at room temperature (the mole ratio of nickel(II) acetate tetrahydrate: sodium hydroxide was 1:2). The mixture was stirred using magnetic stirrer for $4 \mathrm{~h}$ at room temperature. After stirring, the mixture in the beaker was placed 
in a water bath and irradiated with microwave at room temperature for $5 \mathrm{~min}$ ( $15 \mathrm{~s}, 20$ times). A green precipitate formed as a result. The precipitates were washed 5 times with an ethanol solution (the volume ratio of ethanol: water $=1: 1$ ) to remove the impurities. The green powders were dried for $6 \mathrm{~h}$ at $80{ }^{\circ} \mathrm{C}$ in an electric oven, followed by calcination in an electric furnace at $700{ }^{\circ} \mathrm{C}$ for $2 \mathrm{~h}$. In the catalysis experiment, 0.025 $\mathrm{mM}$ 4-nitrophenol was added to $15 \mathrm{~mL}$ of distilled water. Subsequently, $\mathrm{NaBH}_{4}$ and the $\mathrm{NiO} / \mathrm{Ni}$ nanocomposites were added to a 4-nitrophenol solution. The catalytic effect was observed by UV-visible spectroscopy.

\section{RESULTS AND DISCUSSION}

The purity and phase of $\mathrm{NiO} / \mathrm{Ni}$ nanocomposites were analyzed by XRD (Fig. 1). Cubic phase, bunsenite-nanostructured, $\mathrm{NiO} / \mathrm{Ni}$ nanocomposites with high purity were obtained by calcining the as-prepared sample at $700{ }^{\circ} \mathrm{C}$ for $2 \mathrm{~h}$ in an electric furnace ${ }^{25,26}$. Five obvious XRD peaks located at $37.2^{\circ}, 43.3^{\circ}, 62.8^{\circ}, 75.4^{\circ}$ and $79.3^{\circ} 2 \theta$, were assigned to the (101), (012), (110), (113) and (202) peaks, respectively, for cubic NiO (JCPDS44-1159). The three plane indices of $\mathrm{Ni},(111),(200)$ and $(220)$, were also observed at $44.5^{\circ}, 51.9^{\circ}$ and $76.4^{\circ} 2 \theta$, respectively (JCPDS4-850). Overall, XRD confirmed the synthesis of the $\mathrm{NiO} / \mathrm{Ni}$ nanocomposites with crystallinity ${ }^{27}$.

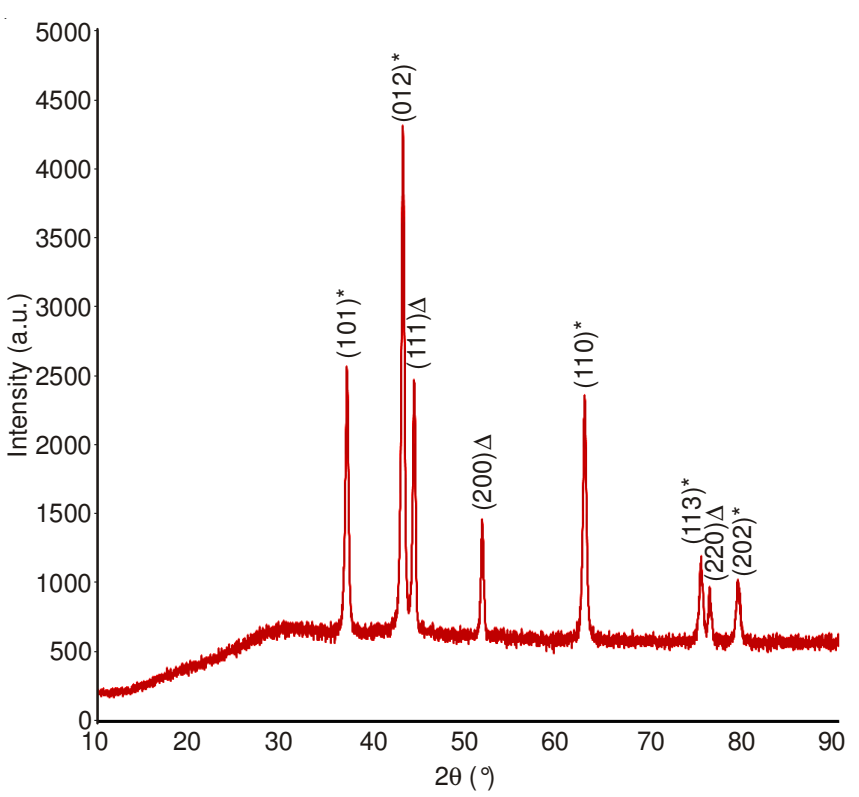

Fig. 1. XRD pattern of the synthesized NiO/Ni nanocomposites; * denotes $\mathrm{NiO}$ nanoparticles, $\Delta$ denotes $\mathrm{Ni}$ nanoparticles

SEM and TEM: Fig. 2 presents a typical SEM image of the $\mathrm{NiO} / \mathrm{Ni}$ nanocomposites. The image revealed a small rock salt-like morphology ${ }^{25}$. In addition, the product revealed homogeneous spherical shaped particles ${ }^{28}$. The formation of these homogeneous particles was examined by microwave irradiation. TEM image showed that the $\mathrm{NiO} / \mathrm{Ni}$ nanocomposites were spherical and cubic shape with a mean diameter of 20-60 nm (Fig. 3). The particle sizes measured from TEM were in good agreement with those estimated from the XRD patterns which had calculated by Scherrer's equation ${ }^{29}$.

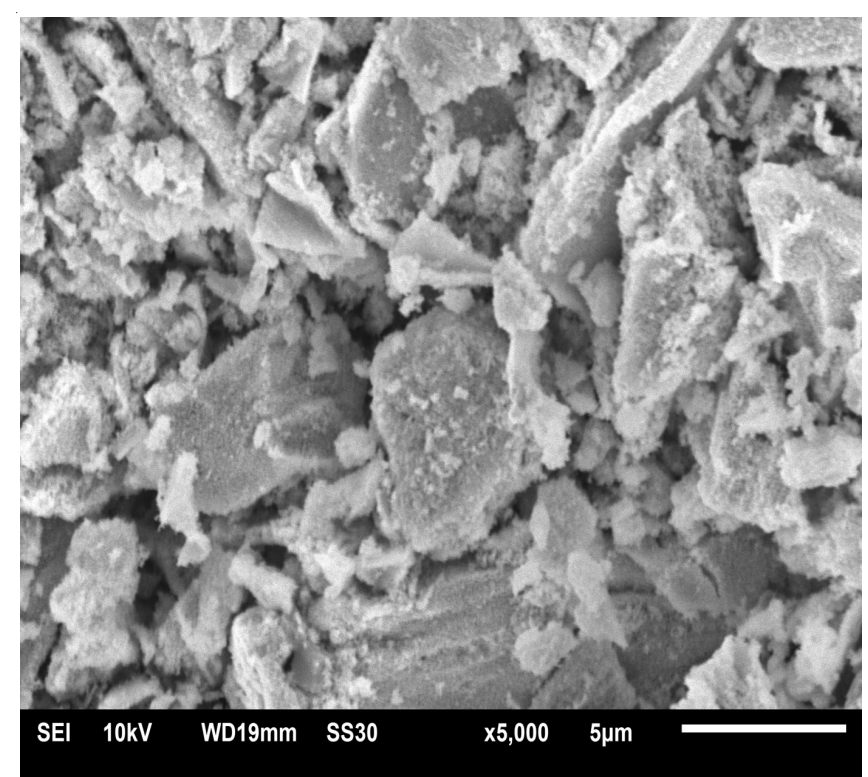

Fig. 2. SEM image of the synthesized $\mathrm{NiO} / \mathrm{Ni}$ nanocomposites

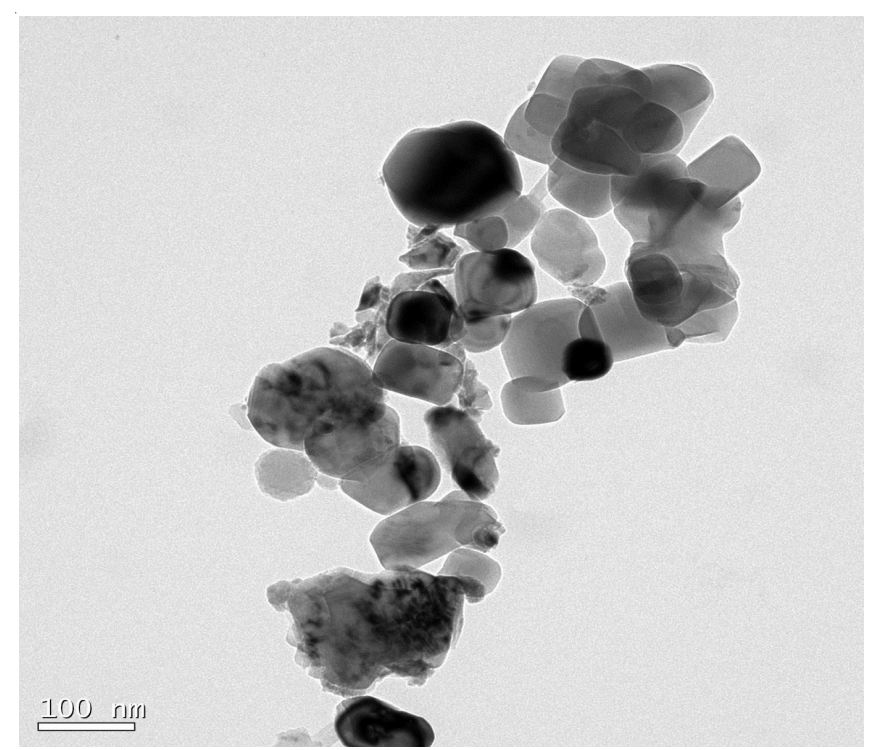

Fig. 3. TEM image of the synthesized NiO/Ni nanocomposites

UV-visible spectroscopy: UV-visible spectroscopy is an important method for revealing the optical properties of semiconductor nanocrystals ${ }^{30}$. In the present study, the UV-visible spectra were used to examine the reduction of 4-nitrophenol to 4-aminophenol. In this reaction, $\mathrm{NaBH}_{4}$ was used as a reducing agent for 4-nitrophenol to change 4-aminophenol at the catalytic reaction of $\mathrm{NiO} / \mathrm{Ni}$ nanocomposites. The change of peak from 320 to $400 \mathrm{~nm}$ was observed after adding the $\mathrm{NaBH}_{4}$, this was attributed to the formation of 4-nitrophenolate ion under alkaline condition ${ }^{31}$. Because of conversion from 4 nitrophenol to 4-aminophenol, the color of the solution also turned from yellow to colorless. As the reaction proceeded, the absorbance peak at $400 \mathrm{~nm}$ lessened gradually and eventually disappeared. At the same time, a new peak at 300 $\mathrm{nm}$ appeared and increased due to the production of 4-aminophenol. Fig. 4 shows the reduction of 4-nitrophenol to 4-aminophenol with $\mathrm{NaBH}_{4}$ using the $\mathrm{NiO} / \mathrm{Ni}$ nanocomposites as a catalyst. 


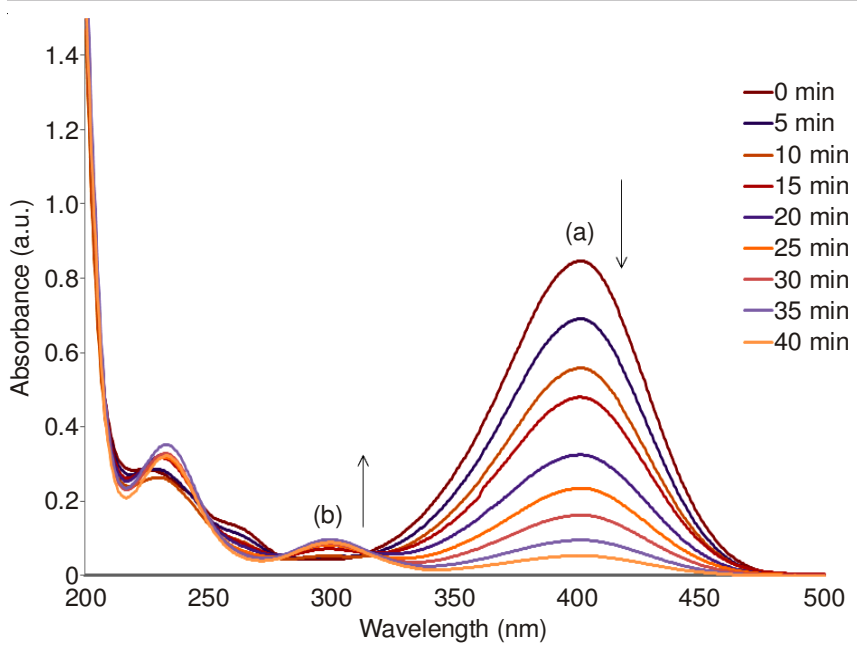

Fig. 4. UV-visible spectrum of 4-nitrophenol reduction in the presence of $\mathrm{NaBH}_{4}$ with heated $\mathrm{NiO} / \mathrm{Ni}$ nanocomposites

\section{Conclusion}

$\mathrm{NiO} / \mathrm{Ni}$ nanocomposites were synthesized by a reaction with nickel (II) acetate tetrahydrate and sodium hydroxide under microwave irradiation followed by calcination in an electric furnace at $700{ }^{\circ} \mathrm{C}$ for $2 \mathrm{~h}$. XRD confirmed that the prepared products were $\mathrm{NiO} / \mathrm{Ni}$ nanocomposites. SEM and TEM showed that the NiO/Ni nanocomposites had a homogeneous spherical and cubic shape with a mean size of 20$60 \mathrm{~nm}$. In addition, the $\mathrm{NiO} / \mathrm{Ni}$ nanocomposites, as a catalyst, promoted the reaction of 4-nitrophenol to 4-aminophenol in the presence of sodium borohydride.

\section{ACKNOWLEDGEMENTS}

This study was supported by Sahmyook University research funding in Korea.

\section{REFERENCES}

1. Z.F. Liu, T. Zhu and J. Zhang, Univ. Chem., 16, 1 (2001).

2. D.Y. Han, H.Y. Yang, C.B. Shen, X. Zhou and F.H. Wang, Powder Technol., 147, 113 (2004).
3. R.N. Bhargava, J. Lumin., 70, 85 (1996).

4. E.T. Goldburt, B. Kulkarni, R.N. Bhargava, J. Taylor and M. Libera, J. Lumin., 72, 190 (1997).

5. R.W. Siegel, Nanostruct. Mater., 3, 1 (1993).

6. E.F. Hilinski, P.A. Lucas and Y. Wang, J. Chem. Phys., 89, 3435 (1988).

7. S.U. Son, I.K. Park, J. Park and T. Hyeon, Chem. Commun., 7, 778 (2004).

8. X.Y. Kong, Y. Ding and Z.L. Wang, J. Phys. Chem. B, 108, 570 (2004).

9. C. Nayral, T. Ould-Ely, A. Maisonnat, B. Chaudret, P. Fau, L. Lescouzères and A. Peyre-Lavigne, Adv. Mater., 11, 61 (1999).

10. Y. Wang, J.Y. Lee and T.C. Deivaraj, J. Mater. Chem., 14, 362 (2004).

11. L.G. Teoh, K.D. Li and Y.H. Liu, Nanosci. Nanotechnol. Lett., 3, 798 (2011).

12. D. Monceau and B. Pieraggi, Oxid. Met., 50, 477 (1998).

13. A.M. Huntz, J. Mater. Sci. Lett., 18, 1981 (1999).

14. A.M. Huntz, B. Lefevre and F. Cassino, Mater. Sci. Eng. A, 290, 190 (2000).

15. D. Levin and J.Y. Ying, Stud. Surf. Sci. Catal., 110, 367 (1997).

16. M. Yoshio, Y. Todorov, K. Yamato, H. Noguchi, J.- Itoh, M. Okada and T. Mouri, J. Power Sources, 74, 46 (1998).

17. M.L. Curri, A. Agostiano, F. Mavelli and M. Della Monica, Mater. Sci. Eng. C, 22, 423 (2002).

18. H.X. Yang, Q.F. Dong, X.H. Hu, X.P. Ai and S.X. Li, J. Power Sources, 79, 256 (1999).

19. Y. Wu, G. Wu and X. Ni, J. Vac. Sci. Technol., 19, 228 (1999).

20. Y. Wang and J. Ke, High Technol. Lett., 3, 92 (1997).

21. E.L. Miller and R.E. Rocheleau, J. Electrochem. Soc., 144, 3072 (1997).

22. Y. Wu, Y. He, T. Wu, T. Chen, W. Weng and H. Wan, Mater. Lett., 61, 3174 (2007).

23. S. M. Karadeniz, A. E. Ekinci, F. N. Tuzluca and M. Ertugrul, Asian J. Chem., 24, 1765 (2012).

24. C. Natarajan, H. Matsumoto and G. Nogami, J. Electrochem. Soc., 144, 121 (1997).

25. R. Mariappan and S. Mahalingam, Asian J. Chem., 25, 3081 (2013).

26. T. Sreethawong, S. Chavadej, S. Ngamsinlapasathian and S. Yoshikawa, Colloids Surf. A Physicochem. Eng. Asp., 296, 222 (2007).

27. X.F. Li, A. Dhanabalan and C.L. Wang, J. Power Sources, 196, 9625 (2011).

28. K. Karthik, G.K. Selvan, M. Kanagaraj, S. Arumugam and N.V. Jaya, J. Alloys Comp., 509, 181 (2011).

29. S. Farhadi and Z. Roostaei-Zaniyani, Polyhedron, 30, 1244 (2011).

30. S.K. Hong, J.H. Lee, J.M. Kim, M.H. Kwon and W.B. Ko, J. Nanosci. Nanotechnol., 11, 593 (2011).

31. J.H. Lee, S.K. Hong and W.B. Ko, Asian J. Chem., 23, 2347 (2011). 